\title{
Los desafíos éticos del discurso político-educativo costarricense en el periodo 2006-2010, basados en el pensamiento dialógico de Martin Buber y el planteamiento de alteridad de Emmanuel Lévinas
}

\author{
The ethical challenges of Costa Rican education-political discourse in the period 2006- \\ 2010, based on Martin Buber's dialogical thinking and approach alterity of \\ Emmanuel Levinas
}

\author{
Esteban J. Beltrán Ulate ${ }^{1}$ \\ Universidad de Costa Rica \\ San Pedro, Costa Rica \\ ESTEBAN.BELTRAN@ucr.ac.cr \\ ORCID: orcid.org/0000-0001-6066-443X
}

Recibido: 21 marzo 2014 Aceptado: 16 junio 2016 Corregido: 18 julio 2016

\begin{abstract}
Resumen: El presente reporte de investigación muestra, de manera sintética, los resultados de una pesquisa presentada en el 2012 para optar por el grado de Licenciatura en Docencia en la Universidad Estatal a Distancia. La exploración de los desafíos éticos en el contexto educativo costarricense desde el planteamiento de Martin Buber y Emmanuel Lévinas es lo que pretende formular la presente investigación, procurando aportar al diálogo nacional el insumo de un elemento filosófico innovador, tenor de un impulso en futuros planteamientos educativos costarricenses que propicien un desarrollo humano cada vez más integral, donde la persona sea considerada en relación armónica con lo existente. Además, se presentan una serie de desafíos éticos que se desprenden de un análisis, en el cual confluyen diversas fuentes de información. La novedad radica en la confluencia de voces y la lectura ética de estos postulados desde el pensamiento de Martin Buber y Emmanuel Lévinas. La meta de la investigación postula un aporte al modelo educativo costarricense, así como a grupos gremiales de la educación y población en general, desde el enfoque de la filosofía del encuentro, desde el planteamiento del diálogo buberiano y el planteamiento de alteridad levinasiano, se puedan encontrar insumos necesarios-para un replanteamiento -tanto desde el aspecto teórico como práctico- en el quehacer educativo nacional.
\end{abstract}

Palabras claves: Educación, alteridad, diálogo, política educativa, ética.

Abstract: This research shows synthetically the results of the study presented in 2012, to qualify for the degree of Bachelor of Teaching at Universidad Estatal a Distancia. This reserach aims to develop

1 Bachiller en Enseñanza de la Música por la Universidad Continental de las Ciencias y las Artes, obtiene la Licenciatura en Docencia en Enseñanza de la Música por la Universidad Estatal a Distancia, actualmente cursa la Maestría Académica en Filosofía por la Universidad de Costa Rica. En el ámbito académico se ha desempeñado como profesor de educación musical en nivel pre-escolar, I y II Ciclo, y III Ciclo y Educación Diversificada, en educación religiosa en III Ciclo y Educación Diversificada, en el Ministerio de Educación Pública, también se desempeña como educador musical en centros educativos privados. Ulteriormente trabajó como instructor musical y luego como coordinador de Programas Especiales en el Sistema Nacional de Educación Musical, del Ministerio de Cultura y Juventud. Huelga indicar que también ha dictado clases en universidades privadas en el área de estudios generales y filosofía. Como investigador ha publicado artículos del ámbito filosófico en revistas académicas nacionales e internacionales. Se ha interesado en el campo del pensamiento filosófico judío y el personalismo. 
and contribute to the national dialogue seeking input from an innovative philosophical element, tener of a boost in future approaches for the Costa Rican educational conducive increasingly integral human development, where the human being is held in harmonious relationship witht he existing. This will be carried out by exploring the ethical challenges in the Costa Rican educational context from the approach of Martin Buber and Emmanuel Levinas. They present a number of ethical challenges that emerge from an analysis, where different sources of information like the novelty lies in the confluence of voices and ethical reading of these principles are presented from Martin Buber and Emmanuel Levinas thoughts. The goal of the research posits a contribution to Costa Rican educational model, as well as education labor groups, from the perspective of the philosophy of the meeting, the approach of dialogue and buberiano levianasiano approach otherness is they may find necessary inputs for rethinking both the theoretical and practical aspects in the national educational work.

Keywords: Education, otherness, dialogue, education policy, ethics.

\section{Introducción}

En la actualidad se manifiesta una crisis en cuanto a lo humano. Esta se traduce en todo aquello en torno al quehacer de la sociedad actual y su origen está marcado por las ambiciones del ser humano, que propician un olvido por el Otro ser, según expresa Lévinas (1973). Estos hechos se evidencian en las constantes disputas entre pueblos e individuos con el fin de ostentar poder. Se puede considerar que no hay consenso en cuanto a un término para definir la época actual; sin embargo, algunos estudios la han llegado a catalogar como postmodernidad. García (2006) la define como una condición de la cultura y cita a Alex Callinicios, quien expresa que el postmodernismo se muestra como la convergencia de tres movimientos culturales: el teórico, el estético y el ideológico.

Gregorio Iriarte (1998), a pesar de enunciar que la postmodernidad es una terminología ambigua, expresa que esta promueve ciertas características importantes a detallar, tales como el individualismo consumista, influenciado por diversas corrientes de pensamiento que exaltan el relativismo moral y la exaltación del cuerpo como mercancía. Además, en estos tiempos existe un exceso de información por parte de los medios de comunicación y se da la idea de primacía de la experiencia sobre el concepto, por lo que se considera este planteamiento como la sobrevaloración de lo práctico por encima de lo que surge de la reflexión y el pensamiento.

En la época postmoderna, el proceso de globalización neoliberal ha desmembrado la soberanía económica de diversos pueblos en Asia, África, América Latina y el Caribe, según expresa Dierckxsens (2010). Específicamente en el caso latinoamericano, se inicia con las políticas de ajuste estructural, que reducen las oportunidades de trabajo de forma local. Esto indica que los países subdesarrollados pasaron a ser los centros de operaciones de diversas empresas de financiamiento extranjero, utilizando los recursos propios de cada pueblo, como apunta el autor: "La Globalización Neoliberal ha sentado las bases de una era de capitalismo de bajos y decrecientes salarios a nivel mundial, de progresiva concentración de la riqueza” (p. 102).

A finales del siglo XX la dinámica dominante era la mundialización de la economía, según expresa Ramonet (1999), basada en la ideología de que solo es posible una determinada política económica con el esquema neoliberal de competitividad, productividad, libre cambio y rentabilidad, es decir, el capitalismo, el cual adquiere fuerza en cuanto a su carácter de 
ampliación de mercado; esta expansión del sistema renunció a su aparente rostro humano de producción para una posterior repartición; su dinámica generó, simplemente, riqueza concentrada y mayor desigualdad entre los pueblos.

A inicios del siglo XXI se muestra la repercusión de la no intervención del Estado en la economía. Dierckxsens (2010) la denomina como la Gran Depresión y la define como el resultado del exceso de capital especulativo o ficticio frente al capital real. El encadenamiento de diversos factores producto de la crisis económico-financiera, que a su vez genera factores negativos para la ecología, específicamente en el uso de energías renovables y no renovables, la agroindustria, aunado a las problemáticas éticas que emergen de las disputas ideológicas. A lo anterior Dierckxsens (2010) lo denomina Crisis de la Civilización.

Esta crisis de carácter civilizacional presenta un elemento detonante, este se comprende como la lógica del mercado neoliberal, su dinámica tiende a introducirse en los espacios sociales, afectando e involucrándose desde lo más cercano como es la economía hasta los espacios políticos, culturales, educativos. A su vez involucra y manipula los medios de comunicación, las jerarquías religiosas, entre otras más entidades (Iriarte 1998).

En el caso de Costa Rica, su política gubernamental demuestra una apertura en el ámbito del libre mercado, ejemplo de ello es la firma de tratados de libre comercio, que posiciona su lógica de mercado dentro de un esquema socioeconómico de características neoliberales, el cual influye en las diversas áreas de la sociedad, sin llegar a brindar una repartición de la riqueza de forma equitativa, lo que va ampliando día con día, la brecha entre estratos sociales, cada vez más difíciles de calificar y que se ven enmarcados en una situación de pobreza, delincuencia, crimen organizado, inseguridad ciudadana, consumo y trasiego de drogas, que afectan, directamente, a la sociedad en general.

A su vez, esta descripción social se ve reflejada en el sistema educativo: agresiones entre estudiantes, desacato a la autoridad del profesorado, indiferencia hacia el proceso enseñanzaaprendizaje por parte de una buena parte de estudiantes y docentes, que dan como resultado una decadencia en la calidad educativa. La Crisis Civilizacional, enunciada por Dierckxsens (2010), también se muestra como una realidad en el ámbito costarricense, dicha crisis va más allá de lo económico-financiero, pues plantea, incluso, desafíos éticos.

En la sociedad occidental postmoderna, con un sistema globalizado de mercado neoliberal que promueve el individualismo consumista, el relativismo moral, el hedonismo, el exceso, la desvalorización del trabajo y resurgimiento de ideas xenofóbicas, resulta imperiosa una educación que propicie el encuentro con la persona, un cambio cualitativo en la conciencia social, con el objetivo de posicionar al ser humano. Esto plantea un giro en el ámbito educativo y podría ser el motor para redireccionar la concepción social del modelo económico hacia un sistema de desarrollo que constituya, a la postre, una nueva civilización. Luego de las experiencias de la I y II Guerra Mundial, la humanidad demostró la capacidad de destrucción masiva que puede alcanzar; desde ese momento se ha dado un resurgimiento de ideas que promueven un replanteamiento de lo ético.

Es en el periodo entre guerras del siglo XX, posterior a la experiencia humana de su capacidad de destrucción masiva, que se da el surgimiento de filosofías que promueven un repunte de la persona humana; en este caso la filosofía dialógica no desprende la dimensión 
ontológica del ser humano, sino más bien, la comprende en cuanto el encuentro con el prójimo, que es a su vez próximo, una ética que asuma el compromiso con el Otro u Otra o, como indica Martin Buber, a partir del reconocimiento del Tú, que es quien llama al Yo.

En este contexto social es importante reconocer el aporte brindado desde la filosofía ante los desafíos sociales del momento y específicamente considerar los planteamientos en el marco filosófico de dos pensadores judíos, Martin Buber y Emmanuel Lévinas, ambos representantes de la filosofía del encuentro o del diálogo. Sus aportes se hallan ligados íntimamente a una visión antropológica que rescata al sujeto, el primero desde la óptica del pensamiento dialógico y el segundo partiendo del planteamiento de alteridad, encuentro del ser en cuanto ser a partir de lo que Lévinas evidencia como el rostro, el cara a cara.

El aporte conceptual del pensamiento dialógico de Martin Buber y del planteamiento de alteridad de Emmanuel Lévinas brindan insumos valiosos para establecer un estudio vinculado al hecho educativo, motivado por el fundamento ético de ambos filósofos, caracterizado por el reconocimiento del Otro y el encuentro con el ser humano, visto este como realidad primera.

Una reflexión ética que permite establecer una línea base sobre la cual responder a las necesidades sociales, las cuales son producto de la crisis generada a partir de las políticas de mercado que han reducido la existencia del ser humano a un simple agente productor consumidor. Esta reducción de lo humano socava la integralidad del ser mismo, en cuanto se postula una supremacía de la experiencia sobre el concepto: con esto se expresa que el pragmatismo ante la vida resulta ser más alentador que el análisis de existencia misma; el ser humano, convertido en un ser para sí, ha dejado de lado el encuentro y, por ende, su modo de relación con las demás personas ha sido interpelado; la visión ética se ha convertido en una ética de la utilidad. Ante esto resulta imperioso reconocer al tú, deshechizarse de la materialidad en la que se ha recluido la humanidad misma.

Han existido antecedentes en Costa Rica que promueven posturas humanistas de diversa índole; sin embargo, es meritorio reflexionar si han alcanzado lo esperado, o si tan solo han permanecido como planteamientos de carácter burocrático. Entre las propuestas educativas en torno al tema de humanidad se encuentra, en primera instancia, la Constitución Política (Asamblea Legislativa de Costa Rica, 1949), base del marco jurídico educativo, específicamente en su título VII donde el Estado asume el compromiso de alfabetización y educación para toda la población sin distingo de edad; así como la Ley Fundamental de la Educación (Asamblea Legislativa de Costa Rica, 1957), la cual enuncia la necesidad de una formación ciudadana que propicie un amor a la patria, conformada por personas conscientes de sus derechos y de sus libertades, asociada a un sentido de responsabilidad y respeto a la dignidad humana. Posterior a esta propuesta, han surgido planteamientos ulteriores por parte del Ministerio de Educación Pública de Costa Rica (MEP), entre los que destaca el proyecto desarrollado entre 2006-2010, intitulado Ética, Estética y Ciudadanía (MEP, 2009a; 2009b; 2009c; PROCESOS, 2009).

Con el fin de establecer un margen cronológico para el presente estudio, el investigador establece como punto de partida el reconocimiento de los desafíos éticos en el campo educativo durante los años 2006-2010, periodo que comprende el gobierno del Dr. Óscar Arias Sánchez con la dirección del Dr. Leonardo Garnier Rímolo en el MEP (MEP, 2002). Se delimita al escrutinio de documentos oficiales del Ministerio de Educación Pública de Costa Rica y 
criterios de la Asociación de Profesores de Segunda Enseñanza (APSE, 2006a; 2006b; 2006c; 2007a; 2007b; 2007c; 2008; 2011) y Asociación Nacional de Educadores (ANDE, 2008a; 2008b; 2008c; 2009; 2010a; 2010b; 2010c; 2010d; 2010e; 2010f). Posteriormente, con base en un análisis de contenido de algunos textos de Martin Buber y Emmanuel Lévinas, se reconocerán los criterios pertinentes para abordar el tema de los desafíos desde la óptica del pensamiento dialógico buberiano y el planteamiento de alteridad levinasiano.

El abordaje de la presente investigación se caracteriza por ser innovador, ya que brinda un sustento teórico-filosófico desde el pensamiento de autores poco estudiados en el medio costarricense, su aporte principal radica en el talante ético de sus posturas. Es necesario enunciar que en el ámbito educativo nacional no se ha utilizado como fundamento la teoría buberiana ni la levinasiana como un mecanismo de contraste o interpretación del hecho educativo, lo que recalca el carácter renovador del presente estudio.

Una exploración de los desafíos éticos en el contexto educativo costarricense desde el planteamiento de estos dos autores representantes de la filosofía del diálogo es lo que pretende formular la investigación; la propuesta radica en aportar al diálogo nacional el insumo de un elemento filosófico innovador, tenor de un impulso en futuros planteamientos educativos costarricenses que propicien un desarrollo humano cada vez más integral, donde la persona humana sea considerada en relación armónica con lo existente. La meta de la investigación postula un aporte al Ministerio de Educación Pública de Costa Rica, así como a grupos gremiales de la educación y población en general, desde el enfoque de la filosofía del encuentro, específicamente desde el planteamiento del diálogo buberiano y el planteamiento de alteridad levianasiano, donde se puedan encontrar insumos necesarios para un replanteamiento tanto desde el aspecto teórico como práctico en el quehacer educativo nacional.

La meta del investigador es responder a la pregunta: ¿Cuáles son los desafíos éticos del discurso político-educativo costarricense en el periodo 2006-2010, basados en el pensamiento dialógico de Martin Buber y el planteamiento de alteridad de Emmanuel Lévinas?

A partir del problema expuesto, el objetivo que traza específicamente este reporte de investigación es el de examinar los desafíos éticos presentes en el discurso político-educativo costarricense, en el periodo 2006-2010.

\section{La educación frente a la crisis ética}

La crisis actual es social, es humana, por tanto ética. De ahí que resulte necesario responder a estos desafíos globales. Un medio para ejercer dicha acción es a través de la educación para responder a los desafíos éticos. El investigador asume una postura desde la cual apela a una concepción de desafíos éticos en el contexto educativo como retos inmanentes a los cánones de comportamiento de los seres humanos en un tiempo y espacio dados, que responden a una política educativa, donde la visión política y económica vigente marca la pauta. Dichos retos deben ser resueltos por la articulación colectiva de la sociedad, se asume un ideal de ciudadano y ciudadana a formar desde una óptica de ética definida que responda a una idea de ética universal, para lo cuál qué mejor opción que realizarlo desde la educación. 
Es irrenunciable la idea de ética ligada al proceso educativo, es una relación inherente; según expresa Savater (1998), la educación es el medio a partir del cual se libera a la humanidad, de lo que él denomina fatalidad, partiendo de una enseñanza de la ética diferente a la tradicional, obviando modelos dogmáticos y fomentando, más bien, un pensamiento libre y crítico, con el fin de formar en la cooperación con los demás individuos y en la capacidad de participar activamente de la vida política. De modo tal que, el principal desafío ético de la educación se reconoce como el despertar la conciencia de libertad y criticidad en el estudiantado, para que, así, se reconozcan como personas con derechos.

\section{Insumos levinasianos y buberianos en la lectura de la crisis}

El carácter dialógico presente tanto en el pensamiento de Martin Buber como en el de Emmanuel Lévinas se evidencia en torno a sus postulados éticos, específicamente a partir de conceptos clave en la comprensión de sus ideas, como "Yo Tú" y el "Cara a Cara", la alteridad; si bien los postulados de ambos autores manifiestan un eje central, evidencian distinciones, que se consideran a lo largo de la investigación.

El pensamiento dialógico de Buber muestra la noción "Yo-Tú" como binomio esencial en el descubrimiento del ser, ya que expresa que la existencia del ser humano está ligada íntimamente a su relación con las demás personas, esto en las antípodas de un modo de existencia referenciado a la experiencia de las cosas, lo que el autor comprende bajo el par binomio "Yo-Ello"; recuperar la relación es el camino, como indica Buber (2006), para atender al problema antropológico. Buber (1984) enuncia que el mundo de las relaciones está constituido por tres esferas.

La primera esfera es la "la vida del hombre con la naturaleza", se considera el encuentro del ser humano con la naturaleza misma, que se caracteriza por estar truncado debido al límite de la palabra; según expresa el autor, "las creaturas se mueven en nuestra presencia" (Buber, 1984, p. 9). La segunda esfera Buber la denomina "la vida del hombre con los hombres", donde la relación se manifiesta por medio de la palabra en la relación persona-persona. La tercera esfera es nombrada como "la comunicación con las formas inteligibles", el ser humano percibe un llamado, "la relación está allí envuelta en las nubes, pero se devela poco a poco" (Buber, 1984, p. 10). Esta esfera, según el pensamiento buberiano, hace referencia al encuentro con Dios cual relación eterna. Esta se logra en la relación con los demás individuos: "La relación con el ser humano es símbolo verdadero de la relación con Dios" (Buber, 1952, p. 77). Las tres esferas del mundo de las relaciones manifiestan la idea de ser humano en encuentro recíproco, con la naturaleza, con sus semejantes y con un ser trascendental.

El deber ser buberiano asume el encarar el rostro, "estar-dos-en-recíproca-presencia" (Buber, 1973, p. 151), este es el hecho fundamental de la existencia humana: la relación. A partir de la comprensión del ser humano con el ser humano, se promoverá una nueva comunidad: en la verdadera comunidad el ser humano encuentra la libertad de su ser y del ser, en el deber ser, esta libertad le permite decidir y comprometerse. Es la consecución de una vida donde prima la relación de diálogo y encuentro con las demás personas, el ser humano es libre, el ser humano confía en el destino de la relación aún sin tener claridad de cuál sea su fin, pero se ofrece al encuentro como acto de libertad. 
En el caso de Emmanuel Lévinas surge la idea de desvelamiento, como encuentro con la huella del Otro, como la necesidad profunda del Yo en su sentido de trascendencia; se comprende esta acción como el descubrir, en lo humano, la esencia de la vida misma, discerniendo, además, que en la condición propia de cada persona se encuentra un elemento que superó lo simplemente material y lo compromete libremente a convivir. La visión de ser humano levinasiana presenta el Yo como sí mismo, en busca del Otro, de la ipsedad a la otredad, es el Yo que trasciende más allá de lo estático. Lévinas (2009) se enfoca en una responsabilidad moral, está comprendida como responsabilidad con el Otro y hacia él.

El ser humano es libertad que parte totalmente y absolutamente hacia el Otro, un camino hacia el Otro sin poder alcanzarlo, infinitamente lejos de él, pero al que puede acceder mediante la huella, su rostro, su mirada (Lévinas, 2006); el ser humano puede encontrar en el indigente, en la prostituta, en el indignado, el reflejo de su humanidad, en este encuentro con el rostro nace la responsabilidad hacia aquella persona que es lejana al que la mira, "Yo soy para el Otro en una relación de diacronía: estoy al servicio del Otro" (Lévinas, 2005, p. 193). El encuentro con el rostro del Otro compromete al ser humano, el Otro se muestra, irrumpe.

El Mismo sujeto recibe al Otro sujeto de modo hospitalario. El Otro es pensar en rostros que hablan (Lévinas, 2009), es pensar en diálogo, en interculturalidad. El encuentro con el rostro del Otro compromete al ser humano, como expresa Robert Bernasconi en Lévinas (2001): "el rostro humano demanda una respuesta ética" (p. xiii). El Otro es alteridad, está más allá del Yo, se manifiesta y demanda un "Heme aquí", como respuesta ética. La noción de alteridad invita a reflexionar la idea de salir de sí mismo hacia el otro, como un viaje en busca de un encuentro, este viaje indica encuentro y responsabilidad con aquel o aquella.

La educación se presenta como el mecanismo por antonomasia para reconfigurar una nueva sociedad, en la que se reconozca al ser humano en toda su integridad y, por ende, con una conciencia de ética, no solo comunitaria sino global, una visión ética que involucre la universalidad de la existencia. Un autor que ha abordado esta temática es el brasileño Leonardo Boff, específicamente en su obra Ética planetaria (Boff, 2001), la cual brinda pautas importantes a considerar en torno a los criterios buberianos y levinasianos, sobre todo por el vínculo de sus postulados.

El autor brasileño apela a la educación de la persona como pilar fundamental sobre el cual desarrollar aspectos humanistas, tales como el compromiso, solidaridad, respeto, comprensión, entre otros. A partir de dicha consideración establece que la educación no debe obviar el desarrollo integral de la persona; al contrario, debe potenciarlo hacia la búsqueda de sentido de vida, identidad y compromiso en sociedad. Reflexiones que manifiestan un vínculo en torno a los criterios de alteridad y diálogo de los autores judíos que sustentan el presente estudio.

Si la impronta de la educación ética es la de promover una formación para una nueva ciudadanía, es imperante que esta educación no sea enfocada a resolver simplemente lo inmediato, sino que apele a una proyección futura, de modo que pueda ir guiando los pasos de la nueva sociedad, y que aunado a esto pueda tener la capacidad de responder a las problemáticas éticas posteriores.

La educación ha de mantener un germen idealista, en el sentido de que ha de estar preparada para el futuro, esto en concordancia con el planteamiento del francés Edgar Morin 
(1999), quien expone que la educación debe plasmar saberes necesarios para la educación del futuro, entre los que destaca la enseñanza para la condición humana, la enseñanza de identidad terrenal y la ética de género humano; en ellos se evidencia un ideal de plasmar, por medio de la educación, una formación capaz de brindar al ser humano los insumos necesarios para responder a los desafíos éticos del futuro.

Costa Rica no escapa de la crisis civilizacional globalizada, como expresa Álvarez (2002), en los años 70 se generó una crisis, en la que la pobreza se duplicó y la tasa de desempleo se triplicó, esto desencadenó una serie de consecuencias que apenas se logró frenar y apaciguar en la década de los 80 y 90; empero "nunca logramos recuperar la tranquilidad... La angustia de la crisis pareció quedarse con nosotros" (p. 8).

La crisis económica ha generado implicaciones en todos los ámbitos, incluso en el campo de las relaciones humanas, ya que la lucha de clases, la angustia por generar capital ha despertado la herencia de los vicios propios de la modernidad, entre los que destaca el ensimismamiento e individualismo; estos, a su vez, han sido agentes desencadenadores de la alergia hacia el Otro, como se expresaría desde un lenguaje levinasiano.

Las relaciones personales en tiempo de crisis evidencian la ausencia de encuentro entre seres humanos, por ende, de diálogo; los individuos se han decantado, en última instancia, por desarrollarse en un ámbito ególatra, como seres para sí, dentro de una dinámica económica de mercado que promueve la competencia y una visión de liberalismo que brinda la aparente oportunidad por salir de la pobreza: "hay una presión competitiva al nivel de lo laboral, empresarial, profesional" (Vargas, 2001, p. 16); sin embargo, esta presión en lugar de ser beneficiosa, promueve una disputa entre grupos de población, como indica el autor: "los lazos de solidaridad se debilitan, sustituidos, entonces, por el resentimiento y la agresividad que derivan de la frustración de sus aspiraciones de consumo" (2001, p. 17). Esto demuestra que la crisis económica genera, a su vez, una crisis ética, pues se promueve la existencia del ser individual en busca de su propio beneficio.

En este contexto de individualidad, la ciudadanía costarricense manifiesta cierto recelo al compromiso político del país, evade la participación activa en la toma de decisiones; empero, arremete con fuertes críticas a las directrices emanadas desde las jerarquías institucionales del gobierno, lo que implica que existe un interés por el rumbo de la Nación; sin embargo, hay falta de convicción en quienes la lideran, por ende, existe una ausencia de un poder del pueblo activo. Esta situación de autodesahucio, por parte de algunas personas de la vida política, posibilita el establecimiento de un modelo de país, liderado por una clase, con un modelo económico determinado. Costa Rica evidencia dicha condición, con el modelo económico neoliberal establecido, que ha desembocado en el ensanchamiento de la desigualdad social.

Esta disparidad en cuanto a la repartición de riqueza en la sociedad ha desencadenado una lucha entre estratos sociales, donde el ser humano no ve el rostro de su semejante, sino que observa en los distintos rostros una posible víctima. Casos como estos desembocan en la denominada inseguridad ciudadana, el ser humano se ha convertido en el lobo que pretende acechar al propio ser humano, las relaciones han pasado a ser opacadas por un deseo de dominación y superación del Otro, quien es visto, incluso, como mercancía de uso.

En este contexto, las fuerzas sociales contestatarias no han logrado detener dicha dinámica, mientras que otros actores del Estado, como el caso de la Iglesia Católica, han 
mantenido un papel de actor silente durante cerca de dos decenios, y han conservado a una parte de la población "encapsulada en una moral desfasada e irreal” (Vargas, 2001, p. 57), lo cual manifiesta un problema para un despertar de las conciencias a favor de un nuevo orden social que responda a las necesidades de una nueva humanidad.

En tal dinámica social, una sección importante de la sociedad costarricense apela a una vía de escape de la realidad, lo que muestra, por otro lado, el grado de cosificación en el que ha degenerado el ser humano. En leguaje buberiano, se puede denominar este hecho como el momento en el cual todo se ha tornado "Ello", desde esta consideración se carece de diálogo, debido a la ausencia de Yo y de Tú, esta capa social hace referencia a la ciudadanía, que intenta escapar de la crisis que afronta la civilización, evadiendo la realidad y asumiendo un alter mundo, a través de grupos religiosos sectarios, uso de drogas, relaciones de codependencia, uniones en las que media la violencia intrafamiliar, uso de redes sociales como realidad alterna, entre diversas manifestaciones.

Ante esto surge la importancia de cuestionar críticamente, ¿qué ha llevado a la humanidad y a la ciudadanía costarricense a querer escapar de la realidad y ocultarse en un submundo?, atendiendo submundo no en su uso tácito, sino más bien a partir de un modo metafórico, desde el cual representar el desinterés por asumir la realidad y afrontarla a partir de su libertad.

Esta descripción social se evidencia en los centros educativos, ya que en ellos se manifiestan las pequeñas sociedades. La disparidad económica, presente en el ámbito costarricense y causante de disputas sociales, se reproduce a su vez en el campo educativo. Los centros educativos se manifiestan como micro sociedades y en su dinámica diaria se evidencian réplicas de la sociedad en general, muestras de violencia entre pares, disputas entre docentes-estudiantes, abuso de poder de docentes, hechos delictivos dentro de las instituciones, entre una gran gama de eventos que denotan la crisis humana.

En este contexto, los desafíos éticos desde el campo educativo, asumen íntegramente la postura establecida en el apartado anterior. Se manifiestan como retos inmanentes e ineludibles, que han de responder de manera cabal a la crisis humana, mediante el establecimiento de un canon de mínimos, sobre los cuales ejercer una función pedagógica, tenor de una idea de estudiante y docente ideal, que asuma el compromiso de encontrar en el otro u otra la naturaleza de su existencia, su humanidad; a partir de este reconocimiento, la articulación ha de ser colectiva, y procurar proyectarse a las necesidades futuras a partir de acciones concretas en el presente.

Sin embargo, para poder establecer una línea general de desafíos éticos en el contexto educativo costarricense, se torna necesario recurrir a una integración de diversos actores que puedan, por su capacidad intelectual y experiencia en el medio, referirse al tema con seguridad y poder contraponer dicha información frente a documentación oficial enfocada en el tema.

La coyuntura social que se está reflejando actualmente en los diferentes centros educativos requiere de una respuesta activa: ese es el principal reto, reconfigurar la educación ética vigente, para responder a los desafíos actuales, como expresa Sequeira (s. f.): "No es posible que ciegamente sigamos obedeciendo a mandatos que nos subsumen cada vez más en la pobreza, en la desesperanza y en la ignorancia” (p. 4). Sin embargo, como expresa Sequeira, 
el Ministerio de Educación Pública ha caído en "sincretismos peligrosos, enfoques que nadie comprende ni puede deleitar y aplicar" (p. 2). Con estas palabras se refiere al planteamiento del enfoque academicista, humanista y constructivista, ya que el MEP no ha sido capaz de concretarlo en el plano real.

La educación institucionalizada ha venido en decadencia, reproduciendo el desorden social, manifestando un vacío ético en detrimento de la convivencia. La escuela, como la denomina Vargas (2001), ha venido a reproducir el modelo estatal, por lo que duplica los valores de autoritarismo y jerarquización. Esto, desde un lenguaje buberiano, denota el modo de relación "Yo-Ello", un modelo distante en el cual un individuo se posiciona sobre el otro, asumiendo a este último como una experiencia, como una cosa.

Responder adecuadamente a los desafíos actuales requiere de ideas claras y distintas en torno a la nueva ciudadanía que se pretende formar: Un ciudadano o ciudadana que afronte los retos sociales y políticos; que se comprometa con sus acciones; que sea capaz de dialogar. Ciudadanos y ciudadanas del mundo que se reconozcan unos a otros a partir del principio fundamental de compartir la humanidad.

\section{Educación y su misión trasformadora}

La tarea de la educación es transformar a una ciudadanía con apatía política, en una ciudadanía comprometida. En la educación se encuentra el lugar para transformar a la sociedad costarricense; en estas circunstancias, el papel del personal docente asume una posición privilegiada, en cuanto se encuentra en la posición de acompañar a niños, niñas y adolescentes de Costa Rica, así como a personas en edad adulta. El personal docente que se adhiera a una postura dialógica, comprenderá que educar implica, en primer lugar, descubrir la humanidad de aquellos y aquellas que le rodean. Es un modelo educativo que rompe con la estructura vertical de conocimiento, en la cual el suleto docente transmite la sabiduría a sus estudiantes, desde la filosofía del diálogo, el conocimiento se genera a partir del encuentro. Este planteamiento implica una reformulación del modelo de clase, en el cual el estudiantado se encuentra aglutinado, en algunas ocasiones en infraestructuras defectuosas, bajo la dirección de personas con falta de apoyo material y logístico.

El personal docente comprometido, en conjunto con la sociedad y la comunidad estudiantil, puede generar un cambio a partir del reconocimiento de la humanidad del Otro; esto implica escapar de la dinámica de mercado que ha logrado derribar la capacidad de encuentro y de diálogo ente los seres humanos. A partir del compromiso recíproco, la educación puede ser el motor generador de un giro antropológico que constituya una nueva ciudadanía costarricense.

La nueva ciudadanía demanda una respuesta al escape de la realidad, a la cosificación, al alter mundo, a la visión del "Ello" como lo principal; la renovada ciudad partirá de un modelo de reconocimiento del Otro, en su diversidad, y en el compromiso mutuo y recíproco en el erguimiento de un modelo país que responda la humanidad integral anhelada.

La sociedad costarricense del Siglo XXI, fragmentada económicamente, con la sombra de la corrupción de parte de figuras políticas, se halla al margen de la dinámica de las políticas neoliberales, las que apelan a un progreso del país, más esto no ha respondido aún 
a las desavenencias entre las clases sociales. La dinámica neoliberal globalizada -tema al cual será necesario referirse en apartados posteriores-, influye claramente en el ideal de ciudadanía a conformar; esto a través de las políticas educativas dictadas desde las jerarquías gubernamentales que deciden en torno al tema educación. De modo tal que el Estado, guiado por políticas neoliberales, asumirá el compromiso de generar a través de su sistema educativo personas capacitadas para responder a la demanda laboral planificada.

El modelo económico subyacente apela a la conformación de una ciudadanía que, si bien responde a las necesidades del mercado, no necesariamente ha de responder a las necesidades de un Estado que se proyecta cimentado en una visión humana integral. Ante este clima crítico-civilizacional, resulta necesario repensar el modelo de educación ética, con el objetivo de que esta responda a los desafíos que demandan los tiempos actuales. Esto no implica que la elaboración de una malla curricular va a solucionar el problema social en general, sino que, a partir de la constante reconfiguración del modelo ético en la educación, se pueda interpelar a la micro-sociedad y que, a partir del micro-cambio, pueda emerger una nueva comunidad.

\section{Lecturas alternas de la realidad educativa}

La política educativa considerada desde el Ministerio de Educación Pública de Costa Rica (MEP, 1994) no es efectiva, pues no es suficiente para las necesidades de la población estudiantil costarricense y los gremios. La Asociación Nacional de Educadores (ANDE) y la Asociación de Profesores de Segunda Enseñanza (APSE) descubren elementos que validan dicho enunciado, tales como indicadores que favorecen una crisis de valores, entre los que destaca la influencia de la crisis económica en manos del neoliberalismo que promueve una ampliación en la brecha social y, por ende, una dificultad para que todas las personas adquieran las mismas oportunidades de desarrollo.

Tanto ANDE como APSE se reconocen en el contexto educativo costarricense como entidades que promueven el reconocimiento de los derechos laborales de los agremiados, de igual manera en sus objetivos se encuentra la mejora de la educación costarricense.

En la pesquisa en cuestión, se realiza un análisis de la realidad en cuanto al tema de los desafíos éticos, desde la óptica de ANDE y APSE; esto, a partir de una entrevista semiestructuradas a especialistas, con interrogantes abiertas, que permiten nuevas preguntas con el fin de precisar algunas ideas, "no todas las preguntas están predeterminadas" (Hernández et al. 2010, p. 418); de las que desembocan las consideraciones consiguientes.

Pese a las iniciativas del MEP, existe una incongruencia en la acción, pues las bases no asimilan los enunciados teóricos, es necesario un replanteamiento de la política educativa, una reforma dirigida por el MEP en la que participen los entes del proceso educativo: las bases, comunidad, padres y madres de familia, estudiantes, docentes, según considera la muestra entrevistada. En la educación los desafíos éticos son retos imperecederos que nunca se erradicarán, ya que conforme se encuentren soluciones a ellos surgirán nuevos retos y continuará el proceso, de modo dialéctico. Frente a esto es necesario lograr una formación integral que despierte al ser humano de la desmotivación en la que vive, pues su vida está limitada en muchos casos a simples procesos bióticos; con esto, el especialista consultado hace 
referencia a la monotonía en la que ha caído el ser humano: nacer, crecer, reproducirse y morir. El sentido de trascendencia, el acto de admirarse ante la naturaleza, ante la esencia misma de la vida han sido acciones que se han dejado de lado, a través de una dinámica de mercado que ha procurado la producción y consumo, más no así la creación y la reflexión crítica.

Ante esto es necesario poder determinar cuál es el ser humano que se anhela, para así, definir qué formación ética diseñar, por consiguiente, es necesario desarrollar creatividad y criticidad en la educación, un conocimiento no desligado de la realidad, pues, aunque existe un alto grado de alfabetización en el país, esto no indica que exista un alto grado de cultura.

La principal debilidad de la formación ética costarricense parte de la concepción de ética ligada a la religión, específicamente al cuadro de valores del cristianismo católico, ya que esto limita un verdadero diálogo entre diversas concepciones de mundo, pues el pueblo costarricense no es solamente católico. La educación en ética está en deuda con las necesidades del pueblo costarricense.

El investigador concluye que el pensamiento dialógico de Martin Buber y Emmanuel Lévinas parten del fundamento de la filosofía del diálogo, a pesar de que presentan diferencias en el desarrollo de su pensamiento, prima en ellos la idea del reconocimiento de la persona y el encuentro por medio de la palabra. En el corpus intelectual de estos dos autores se descubre una fuerte carga ética que postula un humanismo denominado por Lévinas como el humanismo del Otro, a partir de esta idea se vislumbra una sociedad caracterizada como comunidad, donde la persona no busca poseer al Otro sino más bien ser con el Otro; para concretar este ideal se requiere un cambio en la sociedad, el cual se puede brindar por medio de la educación, según concluye el investigador, partiendo de la concepción buberiana y levinasiana, una educación donde se postule una ética del diálogo, una ética de la alteridad.

El análisis de datos de la investigación manifestó que, tanto por parte del MEP y los grupos gremiales ANDE y APSE, no ha existido un abordaje a profundidad respecto a los desafíos éticos y que el tema ha sido emprendido de manera indirecta por las entidades, por tanto, resulta necesario establecer una agenda de trabajo articulada por los diferentes agentes que componen el proceso educativo. La apuesta, por parte del investigador al recurrir a dos autores referentes de la filosofía del diálogo, radica en responder a estos retos desde una óptica humanista, desde la cual se desvele el valor del Otro.

A continuación se describen los desafíos encontrados y las consideraciones a estos mismos a partir del planteamiento dialógico buberiano y consideraciones levinasianas a propósito de la alteridad.

\section{Caracterización de los desafíos éticos}

La interpretación de la información recopilada deriva de sujetos y fuentes de información que se detallan a continuación.

Sujetos especialistas: Lic. Luis Diego Cascante, especialista en filosofía; Dr. Pedro Venegas Jiménez, especialista en educación; MSc. Mario Alberto Segura Castillo, especialista en educación y funcionario del MEP; Alexander Ovares Rodríguez, presidente de ANDE al momento 
del estudio; Mélida Cedeño Castro, presidenta de APSE al momento del estudio. A este grupo de especialistas se les aplicó una entrevista semiestructurada. La entrevista al funcionario del MEP contó con 20 preguntas, a las presidencias de ANDE y APSE con 22 preguntas, al especialista en educación con 22 preguntas, y al especialista en ética con 24 preguntas.

Se indica, a continuación, la relación de las preguntas con los objetivos específicos de la investigación, lo anterior debido a que exponer las preguntas esgrimidas implicaría ampliar el presente reporte, para lo cual es posible para el lector acudir a la investigación para atender especificidades. Entrevista al especialista en filosofía: Preguntas vinculadas a objetivo específico 1 "Determinar los principales postulados teóricos presentes en el pensamiento dialógico de Martin Buber y en el planteamiento de alteridad de Emmanuel Lévinas". Entrevista a funcionario del MEP: Preguntas vinculadas a objetivos específico 2. "Identificar los desafíos éticos presentes en el discurso político- educativo vigente del Ministerio de Educación Pública para el período 2006-2010.”. Entrevista a funcionario de ANDE: Preguntas vinculadas a objetivos específico 4. "Conocer el discurso político educativo respecto a los desafíos éticos que postulan la Asociación Nacional de Educadores (ANDE), y la Asociación de Profesores de Segunda Enseñanza (APSE), para el período 2006-2010." Entrevista a funcionario de APSE: Preguntas vinculadas a objetivos específico 4. Especialista en educación: Preguntas vinculadas a objetivo 2 y 4.

Además se atienden fuentes de información (documentos oficiales del Ministerio de Educación Pública en materia de Política Educativa Costarricense: Política educativa hacia el siglo XXI, Plan de Acción de la Educación para Todos 2003-2015, El centro educativo de calidad como eje de la educación costarricense, Proyecto "Ética, estética y ciudadanía". Aunado a documentos oficiales de ANDE y APSE que hacen referencia a aspectos de política educativa y desafíos éticos), lo anterior expuesto de manera amplia en la tesis Los desafios éticos del discurso político-educativo costarricense en el periodo 2006-2010, basados en el pensamiento dialógico de Martin Buber y el planteamiento de alteridad de Emmanuel Lévinas (Beltrán, 2012).

A partir de la sistematización de información derivada de las fuentes, se despliega el presente artículo como síntesis. El investigador establece como desafíos éticos presentes en la política educativa vigente del Ministerio de Educación Pública entre los años 2006-2010, según la percepción del MEP, los que se citan a continuación:

1. Realizar diagnósticos a los centros educativos

2. Consolidar el sistema educativo con centros educativos de calidad

3. Considerar la ética como un aspecto importante en el proceso educativo

4. Solucionar conflictos sin el uso de violencia

5. Atender la intolerancia ante la diversidad

6. Modificar la actitud negativa de la población respecto a la vida política

7. Erradicar los niveles de desconfianza interpersonales

8. Mejorar los niveles de desarrollo humano del país 
9. Formación de ciudadanos y ciudadanas que respeten la dignidad humana

10. Preparación para una vida en familia digna

11. Propiciar relación armónica entre ser humano y naturaleza

12. Apoyar una convivencia económica

Los desafíos éticos, según el investigador (Beltrán, 2012), son una realidad inminente en la sociedad actual, así como en las anteriores y venideras; cada grupo social tiene, inevitablemente, la disposición para contraer desafíos éticos; estos sucesos interpelan a la comunidad y surge la necesidad de establecer un mecanismo con el cual responder de manera afectiva a la situación que apremia. Los doce desafíos a examinar derivan de la sistematización de información que derivó de los sujetos y fuentes de investigación, esto a partir de las entrevistas y análisis documental, por lo que los desafíos en mención representan una síntesis de dicha sistematización, por tanto algunos de los desafíos en mención son asumidos por más de una de las fuentes o sujetos analizados. Se examinan a continuación los desafíos éticos.

El primero de los desafíos indicados es el de "realizar diagnósticos a los centros educativos", según expresaron las fuentes y sujetos de información el punto focal donde se desarrollan acciones de agresión y violencia se da en centros educativos donde no existe un acompañamiento por parte de las autoridades educativas, permaneciendo así vulnerable la población, en este caso niñas, niños y adolescentes. Desde un enfoque del pensamiento buberiano, los diagnósticos deberían partir de la opinión de todos los actores del quehacer educativo, el Yo-Tú se refleja en el encuentro de todas las personas que componen la comunidad educativa partiendo de las premisas: ¿Qué es el ser humano? ¿Cuál es la visión de ser humano que se pretende educar? ¿Con el proceso de educación vigente, qué tipo de ser humano se está formando?; a su vez, partiendo de una perspectiva levinasiana, los diagnósticos de los centros educativos deberían partir del reconocimiento del Otro como Rostro. Ahora la interrogante que surge es; ¿cuál es el tipo de relaciones entre los diferentes componentes de la comunidad educativa?, ¿se postula una educación de la persona o una educación masificadora?

Como segundo desafío se presenta el de “Consolidar el sistema educativo con centros educativos de calidad”. Teniendo en consideración las ideas de Martin Buber, se podría pensar que la consolidación del sistema educativo como un ente de calidad será efectiva mientras este promueva el reconocimiento del ser humano en torno a su relación Yo-Tú, con la naturaleza, con sus iguales, y con su sentido de trascendencia, planteamientos que se concatenan a los postulados levinasianos que considerarían una calidad de educación manifiesta mediante el resultado social que se genere desde una postura de reconocimiento de la otra persona; por ende, la educación debería considerar como primer elemento dentro de su agenda la formación ética, partiendo del postulado de la alteridad, donde el trato con el Otro sea una salida sin regreso, una responsabilidad infinita para con el Otro, sin esperar lograr recompensa.

Como tercer desafío se anota “Considerar la ética como un aspecto importante en el proceso educativo", es imperioso realizar un análisis de los alcances de la formación ética que se brinda hoy día en Costa Rica. Desde una visión antropológica buberiana se considera la ética como un aspecto de suma importancia como resultado de la relación Yo-Tú, por tanto, 
la educación que parta del reconocimiento de la persona como tal y no como mercancía estará camino a convertirse en una formación para una mejor sociedad. De modo similar apela Lévinas; sin embargo, de un modo más sistemático y profundo, al postular una ética desde la alteridad, el aporte más importante que puede generar el pensamiento levinasiano hacia la educación es el de la ética, como eje del quehacer educativo, una ética de responsabilidad y compromiso con el Otro, sin importar su condición social, económica ni religiosa.

Un tema reiterativo en cada una de las entrevistas a sujetos expertos fue el tema de la violencia en el campo educativo, de ahí que el cuarto desafío que se presenta es el de "Solucionar conflictos sin el uso de violencia". Desde el planteamiento de Martin Buber, la violencia es el resultado de un mundo de relaciones Yo-Ello; partiendo del lenguaje buberiano, cuando el ser humano no ve en su semejante más que una "cosa", la relación será una acción truncada, ante esto es menester lograr un giro en cuanto al tema de relaciones se refiere en el campo educativo, erradicando el trato Yo-Ello, por un Yo-Tú. Esto encuentra eco, a su vez, en las palabras de Emmanuel Lévinas, sobre todo en la idea de "Alergia del Otro", que se vivencia en el campo educativo, pues el ser humano se ha convertido en competencia y motivo de posesión del Otro y viceversa. Ante esta crisis de humanidad, la respuesta desde la óptica del autor es la de descubrir, en el rostro del otro, la huella del infinito y así sentir y dejarse envolver por una responsabilidad infinita hacia el Otro.

Ante el quinto desafío "Atender la intolerancia ante la diversidad", no se puede obviar que la intolerancia se manifiesta de múltiples maneras, como desarrollo de pandillas organizadas, trasiego de droga, violencia intrafamiliar, disputas entre bandas, lo que desemboca en inseguridad ciudadana. Ante esto los postulados buberianos se muestran como un mecanismo de diálogo entre diversas posturas: así, en el conocimiento de la diversidad, la tolerancia es una actitud en torno a la relación dialógica. Desde una lectura levinasiana, el otro, con sus particularidades, revela una responsabilidad que no puede obviarse; la diversidad cultural, sexual, económica no es una frontera para la responsabilidad. Es justamente, a partir de la diversidad, donde se puede y debe hacer patente el desafío de asumir un rol de compromiso social, llamado ético.

La idea de Tú buberiano encuentra afinidad con la idea levinasiana de reconocer al Otro, lo cual él reconoce en la viuda, en el niño y en el huérfano, de manera metafórica, para manifestar que el Otro es un ser humano, una persona que responde a una identidad, por tanto, se ha de recurrir a la idea de respeto a las demás personas sin importar su condición, sin importar su marco religioso o ideológico, pues la comunidad mundial parte de diferentes visiones y es tarea, de quienes anhelen una mejor sociedad, encontrar puntos de diálogo y encuentro, tolerando y respetando la posición del Otro. Desde el campo de la educación, se debe responder a la intolerancia por medio de un ejercicio de compromiso entre actores, mediante un encuentro con la riqueza humana del Otro, que en este caso el investigador denominaría el estudiantado, el cuerpo docente-administrativo, inclusive el personal de aseo y alimentación de la institución.

Otro de los desafíos que se presentaron fue el de "Modificar la actitud negativa de la población respecto a la vida política". La actitud negativa en torno a la vida política es un aspecto modificable desde la educación, en cuanto se ejecute desde primeras instancias un 
diálogo efectivo de manera horizontal entre las diversas personas que componen la comunidad educativa y que luego este accionar se replique en la sociedad en general. Una actitud positiva en cuanto a la vida política se genera en el momento mismo en que las personas que componen la sociedad perciben un diálogo efectivo donde no medien barreras, donde exista un lazo Yo-Tú sin intermediarios; esto se logra desde la educación. Así, desde la óptica del pensador Martin Buber, ser para otro implica una vida política que potencie una vida en comunidad eficaz, mediante una planificación y organización, donde prime el diálogo; sin embargo, como se mencionó anteriormente, esto debe gestarse desde los primeros momentos de la educación formal y, por qué no, desde la educación en familia.

Desde una óptica levinasiana, una relación ética desde la alteridad dispone a la comunidad en general a un compromiso en cuanto al tema político se refiere, pues apunta a un bienestar social; sin embargo, para lograr esto la educación es el mecanismo ideal donde desarrollar un reconocimiento del Otro, a partir del encuentro con el ser humano, una actitud de responsabilidad que lo vincula a trabajar en comunión, partiendo de las normas civiles establecidas democráticamente. De esta manera, una educación que potencie una ética dirigida hacia aquel que está "más allá de mí" será eficaz en miras de una formación para el compromiso político. El centro educativo, por ende, es el ambiente idóneo para fortalecer la formación natural que se gesta en la familia y, en caso de que esta sea ausente, asume el rol preponderante en la formación.

Si no existe compromiso político, el caos se apodera de la sociedad y surgen nuevos desafíos como el de "Erradicar los niveles de desconfianza interpersonales", dicha desconfianza en las demás personas, desde un lenguaje buberiano, es el resultado de un mundo de relaciones Yo-Ello, donde la persona es reducida a simple mercancía, es en esta dinámica social donde se torna necesario un reconocimiento de la persona como un ser capaz de diálogo. En esta relación dialógica es efectivamente donde la humanidad se encuentra consigo misma. Ante esto, la muerte del Otro como un fin se muestra como una característica de la sociedad del siglo XX, por tanto, Emmanuel Lévinas deja entrever en sus textos que la educación ha de responder a la desconfianza social, mediante el reconocimiento del Otro como ser humano, no como posesión; la relación entre el Mismo y el Otro, partiendo de terminología levinasiana, es el mecanismo para el desarrollo de un humanismo del Otro, un planteamiento que apele al reconocimiento como fundamento de la humanidad. Dicha propuesta se halla íntimamente ligada a los presupuestos de la filosofía dialógica, y presta principal atención a los considerandos buberianos y levinasianos.

Atendiendo al desafío de "Mejorar los niveles de desarrollo humano del pais", resulta imperioso considerar: ¿cuál ha de ser el mecanismo social mediante el cual llevar a cabo dicha tarea?, sin duda alguna, ha de ser a través de la educación. Volvemos, entonces, a la importancia de que la educación como sistema al servicio de la persona promueva una formación cimentada en un modelo dialógico, donde el conocimiento sea el perfecto pretexto para hacer humanidad. Un sistema educativo eficaz será el motor de desarrollo de cualquier comunidad del globo. En este caso, el aporte de Buber y Lévinas radica en proponer el diálogoencuentro como metodología y la alteridad como propuesta de vida, ya que una vida para sí no conoce lo que es vivir. 
Un principio ético que presenta la política educativa costarricense y que es, a su vez, un principio planteado desde mucho tiempo atrás, aunque vigente en cada gobierno, es el de “Respeto a la dignidad humana". En este caso la metafísica levinasiana -que no es más que la ética-, responde a este desafío con su frase: "No matarás". El principio por antonomasia de la ética levinasiana radica en el respeto del Otro, en la no posesión del Otro, en este caso Buber brinda una herramienta metodológica en cuanto a su propuesta dialógica para generar espacios de reflexión-acción-reflexión respecto al tema en las comunidades educativas.

¿Cómo responder al desafío "Preparación para una vida en familia digna"?, en estas circunstancias es importante recalcar que debido a la realidad social de Costa Rica, en algunas ocasiones niños y niñas no conocen más familia que el referente que logran captar en las instituciones educativas. Sin embargo, más allá de esta realidad, las instituciones se muestran como micro-comunidades, en las cuales se ensayan muchas conductas posteriores. En estas circunstancias resulta pertinente promover conductas y actitudes que propicien una vida en virtud; un diálogo con el ambiente; con el ser humano y con el sentido de trascendencia; un reconocimiento moral, que fundamente un compromiso y respeto a lo existente, como lo plantean los pensadores mencionados previamente. A partir del compromiso con lo existente, se evidencia una respuesta al desafío "Propiciar la relación armónica entre el ser humano y la naturaleza". Para Buber, el mundo del Ello, sin embargo, no debe ser el centro de acción del Yo, aunado a esto el pensador evidencia que, en la primera esfera de relación, el ser humano percibe un llamado del tú en la naturaleza. El ser humano percibe un tú, que no debe obviar, el que se encuentra en lo existente.

La dinámica social cambia y requiere que las acciones de la ciudadanía muten con ella, los giros políticos y sociales en general se ven interpelados por el mercado; en estas circunstancias, se perfila un desafío que no deja de ser ético, aunque pareciera circunscribirse en un plano económico: "Apoyar una convivencia económica". Es un hecho que el ser humano se relaciona en sociedad y, por ende, los diferentes ámbitos de la sociedad influyen en las personas; en este caso, uno de los desafíos planteados en la política educativa costarricense vigente es el de promover una convivencia económica, entendiendo que la convivencia económica ha de verse en un sentido de economía al servicio del ser humano y no viceversa. Tanto desde Buber como en Lévinas, esta debe ser vista desde la posibilidad de ejercer la responsabilidad con los otros individuos.

Una vez concluido el proceso de examinar los desafíos éticos en el discurso político educativo, el investigador procede a responder al cuarto y último objetivo específico del estudio, el cual reza: "Conocer el discurso político educativo respecto a los desafíos éticos que postulan la Asociación Nacional de Educadores (ANDE) y la Asociación de Profesores de Segunda Enseñanza (APSE), para el período 2006-2010“ (Beltran, 2012, p.25). A partir de la información recopilada de los diferentes sujetos y fuentes de información, el investigador establece como desafíos éticos en el campo educativo costarricense durante el periodo 2006-2010, según la percepción de ANDE y APSE, los que se citan a continuación: Erradicar la conciencia de individualismo, eliminar la competencia desleal entre personas, lograr que el ser humano logre satisfacer sus necesidades, desarrollar una educación que impacte los hogares-la sociedad, crear un modelo pedagógico dialogado (una política educativa en comunión con la comunidad educativa nacional), crear comités para la resolución de conflictos en las instituciones, promover una formación más humanista desde la educación superior, instituir una educación sexual, desligar los intereses del mercado de las políticas educativas. 
Aunado a la identificación de los desafíos éticos en el contexto educativo costarricense durante el periodo citado anteriormente, resulta importante acotar que los representantes de ANDE y APSE consideran como elementos influyentes en la generación de desafíos éticos, los siguientes elementos: La incongruencia en los actos de los referentes sociales; la dinámica del mercado, debido a las políticas económicas implantadas por el gobierno, cuyo esquema es el neoliberal; directrices verticales y unilaterales en cuanto a materia de política educativa emanadas del MEP; la desigualdad socioeconómica; la carencia de capital cultural, falta de identidad; la violencia desde el seno familiar; el uso y manipulación de drogas.

Una vez identificados los desafíos, según los grupos gremiales ANDE y APSE, el investigador procede a establecer una serie de consideraciones a partir de los planteamientos de Martin Buber y Emmanuel Lévinas, desde los postulados de pensamiento dialógico y alteridad, los cuales se elucidan a continuación:

Uno de los desafíos asumidos es el de "Erradicar la conciencia de individualismo", para ello, la educación ha de procurar generar espacios de encuentro entre los diversos actores de la comunidad educativa. Partiendo de la premisa buberiana Yo-Tú, la visión individualista será desplazada en cuanto el ser humano se encuentre con su humanidad, por ende, con sus semejantes, pues la ética desde la alteridad planteada por Lévinas no concibe al ser humano como un ser aislado, sino más bien parte del encuentro con el rostro del Otro. La educación es el mecanismo por excelencia mediante el cual generar un cambio en cuanto una conciencia de individualismo hacia una de compromiso.

Un tema recurrente en la época actual es el de la competencia, esto no es dejado de lado entre los desafíos expuestos, de ahí que se presente como uno de ellos el de "Eliminar la competencia desleal entre personas", ya que, según las personas especialistas entrevistadas, no se habla de una educación en competencias (tendencia que tiene fundamento en los planteamientos del Proyecto Tuning y con influencia en los pilares de la educación abordados por UNESCO en La Educación Encierra un Tesoro, Informe Delors), sino más bien de una competencia entendida como superar a las demás personas sin importar los medios. Esto dista de una postura que pretenda una sociedad justa, se da como resultado de una visión sesgada de relación entre seres humanos, pues la idea de tener se ha posicionado a la del ser. En esta realidad, se materializa el sentido de la vida y las personas se tratan partiendo del Yo-Ello. Lévinas brinda una respuesta desde la ética de la alteridad, visión del Otro como una posibilidad y si bien se puede conocer por el rostro, este tan solo constituye una huella de lo que realmente es, por tanto, la competencia entre personas no representa una posibilidad y debería ser erradicada, pues debe primar la responsabilidad hacia el Otro y el compromiso común, tenor de un bien común. Por tanto, no deben obviarse actos de competencia entre estudiantes o docentes, en fin, entre miembros de la comunidad educativa, sino más bien promover una formación desde la ética de la alteridad.

Además de los expuestos anteriormente, uno de los desafíos éticos en el contexto educativo es "Lograr que el ser humano satisfaga sus necesidades", ya que la realización humana desde la perspectiva buberiana radica en el reconocimiento del Yo a partir de la relación con el Tú; de esto se concluye que el ser humano en cuanto mantenga una relación dialógica con las demás personas se encontrará consigo mismo, colmando sus necesidades sin necesidad de 
buscar, en la materialidad, el sentido de la vida, como expresa Buber, "el hombre no puede vivir sin el Ello. Pero quien vive solo con el Ello no es un hombre” (1984, p. 30). Ante esto, Lévinas deja divisar que la satisfacción del ser humano es su relación de encuentro con el Otro, como acto responsable, expresado a partir de la salida del Mismo, hacia el Otro. En el campo educativo, es velar por un encuentro entre las personas que componen la comunidad educativa, con el fin de que, en la manifestación del rostro, descubran el misterio del infinito y, por ende, la responsabilidad infinita hacia los demás individuos.

Ante el desafío de "Desarrollar una educación que impacte los hogares, la sociedad", la función educativa ha de impactar desarrollando una libertad comprendida como capacidad de entrar en diálogo con las demás personas. Es pertinente desde la posición dialógica buberiana, desde todas las secciones del componente educativo, generar una reflexión en torno al tema de diálogo-encuentro, como eje fundamental del proceso educativo. El eje sobre el cual impactar hogares desde la educación, partiendo de una óptica levinasiana se sintetiza en la ejecución de un modelo educativo que postule como primaria una formación ética desde la alteridad, desarrollando un trabajo vivencial, vinculado a diversas áreas del currículo y en el cual todas las personas que integren la comunidad educativa tengan que posibilidad progresiva de integración.

Uno de los aspectos fundamentales que abordó con hincapié APSE fue el de promover un modelo pedagógico dialogado con las bases. En este contexto resulta atractivo, desde un planteamiento buberiano, responder al desafío de "Crear un modelo pedagógico dialogado, una política educativa en comunión con la comunidad educativa nacional". El pensador vienés fue un ferviente creyente en la capacidad de diálogo entre los seres humanos, por ende, si se reconocieran, en cada niño y niña, las huellas de muchos " $\boldsymbol{T u}$ " que no han nacido aún y que requerirán de un aparato estatal para su formación, resultaría demandante diseñar un modelo que soporte la labor de formar y acompañar a la sociedad en su proceso de desarrollo.

La "creación de comités de resolución de conflictos" resulta atractiva como un mecanismo de acompañamiento en el proceso de transición de un modelo vertical a uno horizontal de educación, por ende, dialógico; sin embargo, la comunidad educativa ha de procurar desarrollar niveles de comunicación y respeto tales que no se requiera de un órgano ejecutor de directrices para el respeto por el ambiente, por el ser humano y por aquello que piensa y siente este.

"Promover una formación humanista desde la educación superior", si bien el desafío derivado de la síntesis de fuentes apunta a la educación superior, la formación ética ha de establecerse de manera continua en el desarrollo humano. La ética es un imperativo que surge del reconocimiento del Otro, en ese rostro a rostro. Una acción que no se debería, en definitiva, obviar sería promover, en diferentes medios, discusiones en torno al tema ético, ya que esto propicia un reconocimiento de la humanidad misma y del compromiso que esto conlleva.

En cuanto al tema de la sexualidad se esgrime un desafío "Instaurar una educación sexual". Este tema ha sido discutido en diversas ocasiones en el medio educativo, sin embargo, requiere de especial atención y ejecución; es un hecho que el tema sexual no puede seguir detrás de un velo, como un tabú. En este caso, desde una óptica levinasiana, se podría 
considerar que la sexualidad ha de manifestarse como encuentro consigo mismo y con el Otro a través de la alteridad, dejando de lado una visión sexual donde se dé primacía a una simplista sobrevaloración del cuerpo, como un hedonismo, sino más bien a una integralidad, desde la cual se desprende la humanidad. Con Lévinas, atendemos a una mirada ética desde un ser encarnado y posicionado desde su corporeidad; la imagen del pobre, la viuda y el huérfano, puede ser transportada a otros ámbitos; la diversidad sexual es una realidad y la respuesta ética desde la educación ha de ser un llamado al compromiso responsable y no a la invisibilización del hecho. El ser humano es un ser sexuado, su sexualidad es una inherencia que no debe ser mancillada, sino acompañada para el desenvolvimiento pleno de su persona.

Otro aspecto importante a valorar es el "desligar los intereses del mercado de las políticas educativas". Este desafío presenta gran dificultad, pues el sistema educativo no dejará de ser un aparato del sistema estatal, mediante el cual se forma a la ciudadanía que requiere el Estado según sus intereses políticos; desligar los intereses del mercado se podría interpretar en el contexto social actual, que las políticas neoliberales no incurran en intervenir procesos curriculares. Sin embargo, el modo más eficaz para subsanar este desafío sería mediante el desarrollo de un Estado que vele por una economía de carácter socialista, ¿por qué han de vivir unos como ricos y otros como esclavos en una nación?, ¿dónde está el compromiso?, ¿dónde está el Tú?

$\mathrm{Si}$ bien con las tesis expuestas anteriormente se denota una respuesta, por parte del investigador a los diferentes desafíos esgrimidos por ANDE y APSE, él mismo asume la libertad de presentar una serie de desafíos a propósito del tema enunciados por los especialistas en filosofía y educación, que fungieron como sujetos expertos, información que no está circunscrita dentro del objetivo tercero; pero que resulta conveniente incorporar a propósito de los desafíos y la consideración de estos desde la óptica buberiana y levinasiana. Dichos desafíos, generados a través de las entrevistas realizadas al especialista en filosofía y educación, se mencionan a continuación: Definir el ideal de ser humano que la sociedad anhela, promover un diálogo intercultural al interior de la sociedad costarricense (iniciando desde las instituciones educativas), respetar la diversidad y potenciar en ella la búsqueda de consensos, suscitar una nueva visión de docente-estudiante (obviando el sistema directivo, vertical, desarrollando un giro hacia una relación de diálogo, horizontal de respeto mutuo), procurar la formación de un criterio de compromiso humano (en el estudiantado y profesorado), la formación ética de estudiantes no debe estar sustentada únicamente bajo los criterios de una religión determinada.

Un desafío fundamental dentro de los analizados es el de "Definir el ideal de ser humano que la sociedad anhela", pues esto es requisito para considerar los desafíos que este posee; sin embargo, acaece una paradoja: ¿Cómo el ser humano que no está definido puede definir al ser humano que anhela? Ante esto, resulta pertinente analizar la pregunta perenne de Buber: ¿Qué es el ser humano? Esta interrogación no debe desaparecer de la existencia misma, el cuestionarse acerca de su sentido es un requisito elemental, para reconfigurarse día tras día; en este caso, desde una óptica buberiana, el ser humano se comprende mediante compromiso y existencia con los demás individuos, a través de relaciones mediante el Tú. En este sentido, el ideal de ser humano ha de ser un ejercicio reflexivo constante, en dialogo horizontal con la comunidad en general. La definición de ser humano anhelado no ha de ser una conceptualización rígida e inalterable, sino más bien reconfigurable, por lo que ha 
de responder a todas las personas por igual, sin importar la diversidad de la cual es parte toda la humanidad. Con ello, se estaría abogando a su vez por el desafío de “Respetar la diversidad y potenciar en ella la búsqueda de consensos" y, también, el de "Promover un diálogo intercultural a lo interno de la sociedad costarricense, iniciando desde las instituciones educativas".

Todos estos desafíos en el ámbito educativo encuentran asidero en el desafío de "Suscitar una nueva visión de profesorado-estudiante, que obvie el sistema directivo, vertical y desarrolle un giro hacia una relación de diálogo, horizontal de respeto mutuo". Desde el planteamiento buberiano, docentes y estudiantes no han de ser sujetos extraños, sino -más bien- compañeros y compañeras en un proceso de desarrollo para el bienestar de la comunidad, por tanto, de esa dinámica surgirá un criterio de compromiso humano en general.

Como último desafío a considerar "La formación ética del estudiantado no debe estar sustentada únicamente por los criterios de una religión determinada”. Este desafío, igual que el tema de la sexualidad, ha sido reflexionado desde diferentes ámbitos en la sociedad: ¿Qué tan pertinente es que se impongan los criterios de la religión católica sobre el Estado costarricense?, teniendo en consideración que el Estado costarricense, en su carácter democrático, ha de velar por el bienestar de la totalidad de sus miembros. La reflexión acerca de lo ético no es campo de estudio y reflexión de una religión determinada, a su vez, el Estado ha de promover un diálogo entre todas las partes, para gestionar una formación ética que procura la configuración de una ciudadanía integral, que responda a principios mínimos de convivencia sin que su credo interfiera, elementos tan primordiales como lo son el respeto al medio, a sí misma y a sus iguales. La ética es un tema que involucra a la totalidad de agentes de la comunidad, por lo que disponer de voces oficiales puede afectar un verdadero y óptimo diálogo. Las reflexiones en torno a consideraciones éticas han de gestarse en un ámbito de relación "Yo-Tú", donde la idea de rostro levinasiana invite a considerar al Otro, como la persona cristiana, protestante, judía, musulmana, agnóstica o atea.

\section{Conclusiones}

Los desafíos son realidades dinámicas. Con esto el investigador quiere manifestar su carácter no estático, ya que mutan según el contexto, la realidad social de la cual es parte la comunidad educativa. Estos desafíos, si bien cambiantes, evidencian una característica fundamental: se manifiestan en modos de relación dual. De manera más clara, los desafíos serán siempre vertidos en cuanto la relación del ser humano consigo mismo, del ser humano con sus semejantes (ser humano), ser humano con la naturaleza, ser humano con su sentido de trascendencia. Así, como los desafíos son cambiantes, la sociedad debe promover espacios de diálogo horizontal y análisis democrático. Dichos desafíos son inherentes al quehacer humano, no pueden negarse. Como síntesis, se recalca en la necesidad de promover la reflexión acerca de los desafíos éticos con el objetivo de trazar el camino hacia una sociedad cada vez más humana, a partir del diálogo, reconocimiento y compromiso recíproco. La relación entre educación y ética es consubstancial, pues ambas nociones son encarnadas en el ser humano; frente a la crisis social, el giro ha de ser antropológico, este es el aporte que pretende presente reporte de investigación, que tiene como horizonte el texto original, la tesis inédita, presentada en el 2012 e intitulada: Los desafios éticos del discurso político-educativo 
costarricense en el periodo 2006-2010, basados en el pensamiento dialógico de Martin Buber y el planteamiento de alteridad de Emmanuel Lévinas.

\section{Referencias}

Álvarez, D. (2002). Un nuevo camino para Costa Rica. San José: EUNED.

Asociación Nacional de Educadores (ANDE). (Agosto, 2008a). Valores. La voz de Ande, $\mathrm{N}^{\circ}$ 345 , p. 19.

ANDE (Octubre, 2008b). Trabajar estratégicamente para prevenir la violencia. La voz de Ande, $\mathrm{N}^{\circ} 347$, p. 2.

ANDE (Noviembre, 2008c). Un recorrido de logros alcanzados. La voz de Ande, $\mathrm{N}^{\circ}$ 348, p. 2.

ANDE (Julio, 2009). Su aporte se convierte en beneficios. La voz de Ande, № 353, p. 2.

ANDE (Febrero, 2010a). Una política educativa que no debe esperar. La voz de Ande, № 359, p. 2.

ANDE (Febrero, 2010b). Costa Rica enfrenta serios desafíos en materia educativa. La voz de Ande, $\mathrm{N}^{\circ} 359$, pp. 16-17.

ANDE (Febrero, 2010c). Docentes son pieza clave para mejorar la convivencia en los centros educativos. La voz de Ande, № 360, pp. 16-17.

ANDE (Febrero, 2010d). Docentes no cuentan con las herramientas para abordar el tema de VIH-Sida en las aulas. La voz de Ande, $\mathrm{N}^{\circ} 361$, pp.16-17.

ANDE (Junio, 2010e). Lo que espera la ANDE del nuevo gobierno. La voz de Ande, No 363, p. 2.

ANDE (Agosto, 2010f). Violencia en los centros educativos. La voz de Ande, $\mathrm{N}^{\circ}$ 365, p. 2.

Asamblea Legislativa de Costa Rica. (1949). Constitución Política de la República de Costa Rica. Costa Rica: Imprenta Nacional.

Asociación de Profesores de Segunda Enseñanza (APSE). (Abril-mayo, 2006a). Apse Informa. Recuperado de http://www.apse.or.cr/webapse/09informa.htm

APSE. (Junio-julio, 2006b). Apse Informa. Recuperado de http://www.apse.or.cr/ webapse/09informa.htm 
APSE. (Diciembre, 2006c). Apse Informa. Recuperado de http://www.apse.or.cr/ webapse/09informa.htm

APSE. (Abril, 2007a). Apse Informa. Recuperado de http://www.apse.or.cr/webapse/09informa. htm

APSE.(Agosto, 2007b).ApseInforma. Recuperado dehttp://www.apse.or.cr/webapse/09informa. htm

APSE. (Noviembre, 2007c). Apse Informa. Recuperado de http://www.apse.or.cr/ webapse/09informa.htm

APSE. (Noviembre 2008). Apse Informa. Recuperado de http://www.apse.or.cr/ webapse/09informa.htm

APSE. (2011). ¿Qué hacer con la violencia en las aulas?. Recuperado de http://www.apse.or.cr/ webapse/2011/archivo/cp/06cp.htm

Asamblea Legislativa de Costa Rica (1957). Ley Fundamental de Educación. Recuperado de: http://www.apse.or.cr/webapse/legdoc/leg02.htm

Beltrán, E. (2012) Los desafíos éticos del discurso político-educativo costarricense en el periodo 2006-2010, basados en el pensamiento dialógico de Martin Buber y el planteamiento de alteridad de Emmanuel Lévinas (Tesis de maestría). Universidad Estatal a Distancia, Costa Rica. Recuperado de http://bit.ly/2bgJp98

Buber, M. (1952). La vie en dialogue. Lyon: Editions Montaigne.

Buber, M. (1973). ¿Qué es el hombre? México: Fondo de Culturas Económica.

Buber, M. (1984). Yo y Tú. Buenos Aires: Ediciones Nueva Visión.

Buber, M. (2006). Caminos de utopía. México: Fondo de Culturas Económica.

Boff, L. (2001). Ética planetaria desde el Gran Sur. Madrid: Editorial Trotta.

Dierckxsens, W. (2010). Siglo XXI: Crisis de una civilización: ¿ Fin de la historia o el comienzo de una nueva historia? San José: Editorial Departamento Ecuménico de Investigación (DEI). 
García, G. (2006). La postmodernidad y sus modernidades: Una introducción. San José: Editorial Universidad de Costa Rica.

Hernández, R., Fernández, C., y Baptista, P. (2006). Metodología de la investigación. México: McGraw-Hill Interamericana de México.

Iriarte, G. (1998). Postmodernidad, neoliberalismo, globalización. Bolivia: CEPROMI.

Levinas, E. (1973). Humanismo del otro hombre. España: Siglo veintiuno editores.

Levinas, E. (2005). Dios, la muerte y el tiempo. Madrid: Ediciones Cátedra.

Levinas, E. (2006). Totalidad e infinito. Salamanca: Ediciones Sígueme.

Levinas, E. (2001). Existence and Existents. Pennsylvania: Duquesne University Press.

Levinas, E. (2009). Éthique et infini. Paris: Litografia Rosés.

Ministerio de Educación Pública (MEP). (1994). Política Educativa hacia el Siglo XXI. Recuperado de http://www.mep.go.cr/CentroDeInformacion/DOC/ politicaeducativasigloXXI-226200914446.pdf

MEP. (2002). Plan de acción de la educación para todos 2003-2015. Recuperado de http:// www.oei.es/quipu/costarica/PLANDEACCION2003_2015.pdf

MEP. (2009a). Resumen Proyecto Ética, Estética y Ciudadanía. Recuperado de http://www. mep.go.cr/downloads/RESUMEN\%20EEC\%20abril\%202009.pdf

MEP. (2009b). Programa de Estudio de Educación Cívica para III Ciclo y Diversificada. Recuperado de http://www.mep.go.cr/downloads/ReglamentoEvaluacion/Programa\%20 de\%20Estudios\%20de\%20Educación\%20Cívica\%20para\%20III\%20Ciclo\%20y\%20 Educación\%20Diversificada.pdf

MEP. (2009c). Ética, estética y ciudadanía: Una educación para saber vivir y saber convivir, Leonardo Garnier, Ministro de Educación. Recuperado de http://www.mep.go.cr/ downloads/articulos_ministro/09_etica_estetica_ciudadania.pdf

Morin, E. (1999). Los siete saberes necesarios para la educación del futuro. París: Editorial Organización de las Naciones Unidas para la Educación, UNESCO. 
PROCESOS. (2009). Proyecto: Educación en ética estética y ciudadanía. Recuperado de http://www.procesos.org/Descarga/Cuadernos/CT\%202009-02\%20Sistematizacion\%20 cultura\%20politica.pdf

Ramonet, I. (1999). Un mundo sin rumbo. Crisis de fin de siglo. España: Editorial Debate.

Savater, F. (1998). La educación es el momento adecuado de la ética. Recuperado de http://www.analitica.com/bitblio/savater/education_etica.asp

Sequeira, A. (s. f.). La construcción del currículo: Una opción ética. Recuperado de bibliotecavirtual.clacso.org.ar/ar/libros/cielac/human/seque.rtf

Vargas, L. (2001). Costa Rica hoy: Una sociedad en crisis. San José: Editorial EUNED. 